\title{
Rancang Bangun VoIP Server Menggunakan Trixbox CE
}

\author{
Aldio Muhammad ${ }^{1 *}$, Andy Triwinarko ${ }^{2 * *}$, Agus Fatulloh ${ }^{3 *}$ \\ * Teknik Informatika, Politeknik Negeri Batam \\ ** Teknik Multimedia Jaringan, Politeknik Negeri Batam \\ andy@ polibatam.ac.id ${ }^{2}$, agusf@ polibatam.ac.id ${ }^{3}$
}

\begin{tabular}{|c|c|}
\hline Article Info & ABSTRACT \\
\hline $\begin{array}{l}\text { Article history: } \\
\text { Received 07-03-2017 } \\
\text { Revised 09-04-2017 } \\
\text { Accepted 06-05-2017 }\end{array}$ & $\begin{array}{l}\text { Perkembangan teknologi internet sangat dirasakan sekarang ini dalam kehidupan } \\
\text { sehari-hari baik semua kalangan masyarakat bahkan sudah menjadi kebutuhan } \\
\text { primer untuk kalangan tertentu, seperti kalangan pendidikan, ekonomi, kesehatan, } \\
\text { dan sebagainya. Teknologi sekarang untuk bertukar suara sudah banyak digunakan } \\
\text { oleh masyarakat, salah satunya adalah telepon tradisional, yaitu berkomunikasi baik }\end{array}$ \\
\hline $\begin{array}{l}\text { Keyword: } \\
\text { VoIP, } \\
\text { IP, } \\
\text { Trixbox, } \\
\text { Smartphone. }\end{array}$ & $\begin{array}{l}\text { menggunakan telepon kabel ataupun telepon genggam semua orang dapat } \\
\text { berkomunikasi di dalamnya. Namun jika kita menggunakan panggilan telepon } \\
\text { tradisional, selain tarif yang mahal juga letak geografis yang menentukan besar } \\
\text { kecilnya biaya yang harus dikeluarkan. Dengan adanya teknologi Voice Over } \\
\text { Internet Protocol (VoIP) yang murah untuk berkomunikasi baik voice call maupun } \\
\text { video call menggunakan internet yang berjalan melalui jaringan IP (Internet } \\
\text { Protocol), ini membuat sebuah keuntungan sendiri bagi kalangan yang selalu } \\
\text { membutuhkan alat komunikasi di lingkungan kerjanya, karena biaya lebih murah } \\
\text { juga bersifat secara global, tidak mengacu terhadap jarak alamat yang dituju. } \\
\text { Teknologi telepon ini mengubah suara menjadi kode digital melalui jaringan paket } \\
\text { data, bukan sirkuit analog seperti telepon biasa. Implementasi VoIP Server } \\
\text { menggunakan sistem operasi gratis Linux Trixbox CE yang mampu diakses client di } \\
\text { OS Multi-Platform dan client berbasis Mobile Phone (Android). }\end{array}$ \\
\hline
\end{tabular}

Copyright $(92017$ Journal of Applied Informatics and Computing. All rights reserved.

\section{Pendahuluan}

Teknologi internet modern sekarang ini sangat berkembang pesat khususnya dalam bidang sistem informasi dan telekomunikasi. Internet sekarang ini sangat diperlukan sehari-hari untuk semua kalangan masyarakat bahkan sudah menjadi kebutuhan primer untuk kalangan tertentu, seperti kalangan pendidikan, ekonomi, kesehatan, dan sebagainya. Teknologi sekarang untuk bertukar suara sudah banyak digunakan oleh masyarakat, salah satunya adalah telepon tradisional, yaitu berkomunikasi baik menggunakan telepon kabel ataupun telepon genggam semua orang dapat berkomunikasi di dalamnya. Namun jika kita menggunakan panggilan telepon tradisional, selain tarif yang mahal juga letak geografis yang menentukan besar kecilnya biaya yang harus dikeluarkan.

Perkembangan teknologi VoIP sekarang sangat pesat, hal ini juga dipengaruhi oleh protokol-protokol yang handal seperti SIP (Session Innitiation Protocol). Munculnya teknologi Voice Over Internet Protocol (VoIP) yang murah untuk berkomunikasi baik voice call maupun video call menggunakan internet yang berjalan melalui jaringan IP (Internet Protocol), ini membuat sebuah keuntungan sendiri bagi kalangan yang selalu membutuhkan alat komunikasi di lingkungan kerjanya, karena biaya lebih murah juga bersifat secara global, tidak mengacu terhadap jarak alamat yang dituju. Teknologi telepon ini mengubah suara menjadi kode digital melalui jaringan paket data, bukan sirkuit analog seperti telepon biasa.

VoIP Server merupakan sebuah teknologi telekomunikasi yang sudah lama, namun perkembangannya untuk di zaman sekarang sangatlah dibutuhkan. VoIP Server menyediakan layanan telepon berbasis IP (Internet Protocol). Layanan VoIP ini sangat berguna dan sangat banyak manfaat untuk dapat di implementasikan karena VoIP Server ini adalah gratis (Open Source), hemat biaya dalam penggunaan telepon 
selular. Namun terdapat juga beberapa beberapa penyedia layanan internet yang menjual layanan VoIP yang berbayar, dengan menawarkan kelebihan dibandingkan dengan sistem operasi gratis.

Penelitian ini dikembangkan dari beberapa referensi yang telah didapat dan berhubungan dengan objek permasalahan. Pada penelitian kajian VoIP [1] menjelaskan tentang kajian bagaimana suara (sinyal analog) akan dirubah menjadi sinyal digital untuk dapat dilewatkan jaringan IP (Internet Protocol) dan menjelaskan bagaimana sebuah sinyal informasi dari satu sumber data disampaikan ke tujuan melalui jaringan IP, juga menjelaskan bagaimana cara kerja VoIP secara umum di gedung PPTIK dan gedung MPKD UGM [7].

Pada penelitian yang berjudul "Implementasi VoIP Over VPN Menggunakan IPv4 (Studi Kasus Politeknik Telkom)“ menerangkan bagaimana membuat komunikasi suara pada VoIP melewati VPN untuk komunikasi mahasiswa dan dosen, meskipun keduanya tidak dalam kampus Politeknik Telkom, kemudian peneliti juga menguji dengan analisis terhadap jalur komunikasi VoIP yang mungkin bisa terjadi penyadapan (Sniffing) dan membandingkan antara VoIP tanpa jalur VPN dan menggabungkan VoIP dengan melalui jalur VPN, kemudian menganalisis bentuk penyadapan (Sniffing) yang dapat terjadi pada kedua jalur komunikasi VoIP [6].

Pada penelitian yang berjudul "Teknik Keamanan Voice Over WLANs 802.11" juga menggunakan VPN pada jaringan lokal menggunakan Linux Trixbox sebagai salah satu komunikasi data yang aman, dengan mekanisme IPSec yang menyediakan enkripsi untuk paket UDP dan TCP Traffic [9].

Pada penelitian yang berjudul "Implementasi Server VoIP Untuk Komunikasi Di PT. Lintas Data Prima" penulis mengimplementasikan jaringan VoIP menggunakan Asterisk dengan sistem operasi Linux Elastix, serta mengimplementasikan jaringan VoIP di PT. Lintas Data Prima untuk dapat terhubung dengan jaringan Telkom, Yahoo Messager, G-Talk yang kesemuanya menggunakan VoIP Gateway sebagai penghubung dengan Server VoIP PT. Lintas Data Prima [5].

Sesuai dengan penelitian yang telah dilakukan diatas maka dari itu penulis ingin mendesain dan mengimplementasikan aplikasi Asterisk di dalam sistem operasi Linux Trixbox2.8.0.4 sebagai VoIP Server yang mampu memberikan layanan komunikasi telepon murah antar client.

\section{LANDASAN TEORI}

\section{A. Voice Over Internet Protocol}

VoIP (Voice over Internet Protocol) adalah teknologi berupa hardware dan software yang memungkinkan percakapan telepon dengan menggunakan jalur komunikasi data pada suatu jaringan komputer. Teknologi ini dengan merubah suara menjadi format digital tertentu sehingga dapat dilewatkan melalui jaringan IP.

Kelebihan dari penggunaan VoIP memiliki keuntungan seperti dari segi biaya, jelas lebih murah dibandingkan dengan tarif telepon analog, karena jaringan IP bersifat global sehingga untuk hubungan Internasional dapat ditekan hingga
$70 \%$. Serta biaya maintenance dapat dikurangi karena voice dan data network terpisah.

VoIP juga memiliki kekurangan sebagai berikut:

- Delay, adalah interval waktu saat suara mulai dikirimkan oleh pemanggil menuju penerima panggilan yang disebabkan salah satunya oleh konversi suara analog menjadi data-data digital.

- Jitter, adalah variasi yang ditimbulkan oleh delay, terjadi karena adanya perubahan terhadap karakteristik dari suatu sinyal sehingga menyebabkan terjadinya masalah terhadap data yang dibawa oleh sinyal tersebut.

- Packet Loss, adalah hilangnya paket data yang sedang dikirimkan disebabkan karena jitter atau karena adanya permasalahan di perangkat-perangkat jaringan seperti router atau jalur komunikasi yang terlalu padat penggunanya.

Protokol untuk VoIP:

- H.323, adalah salah satu dari rekomendasi ITU-T (International Telecommunications Union Telecommunications). H.323 merupakan standar yang menentukan komponen, protokol, dan prosedur yang menyediakan layanan komunikasi multimedia. Layanan tersebut adalah komunikasi audio, video, dan data realtime, melalui jaringan berbasis paket (packet-based network). (Tabratas Tharom, 2001;64)

- $\quad$ SIP, adalah suatu signalling protocol pada layer aplikasi yang berfungsi untuk membangun, memodifikasi, dan mengakhiri suatu sesi multimedia yang melibatkan satu atau beberapa pengguna. Sesi multimedia adalah pertukaran data antar pengguna yang bisa meliputi suara, video, dan teks.

\section{B. Trixbox $C E$}

Trixbox CE (Community Edition) adalah sebuah VoIP Phone System berbasiskan sistem open source paling populer didunia karena mengkombinasikan paket-paket open source telepon terbaik yang disertakan didalam sistem operasi tersebut. Sebelumnya kebanyakan user yang ingin mengimplementasikan teknologi VoIP harus dengan usaha yang besar dikarenakan harus menjadi seorang programmer untuk menghadapi user interface yang tidak friendly, oleh karena itu untuk mengatasi masalah seperti itu diluncukannya Trixbox dengan penggunaan yang sangat mudah karena menu utama yang berbasiskan web untuk mengkonfigurasi dan mengatur sistem, serta paket-paket untuk VoIP Server dijadikan dalam satu bundle dengan operating system CentOS sehingga menjadi sistem TrixboxCE. 


\section{Analisis Perancangan}

Semua baris pertama pada permulaan paragraf harus diformat menjorok ke dalam, dengan format rata kiri dan kanan (justified).

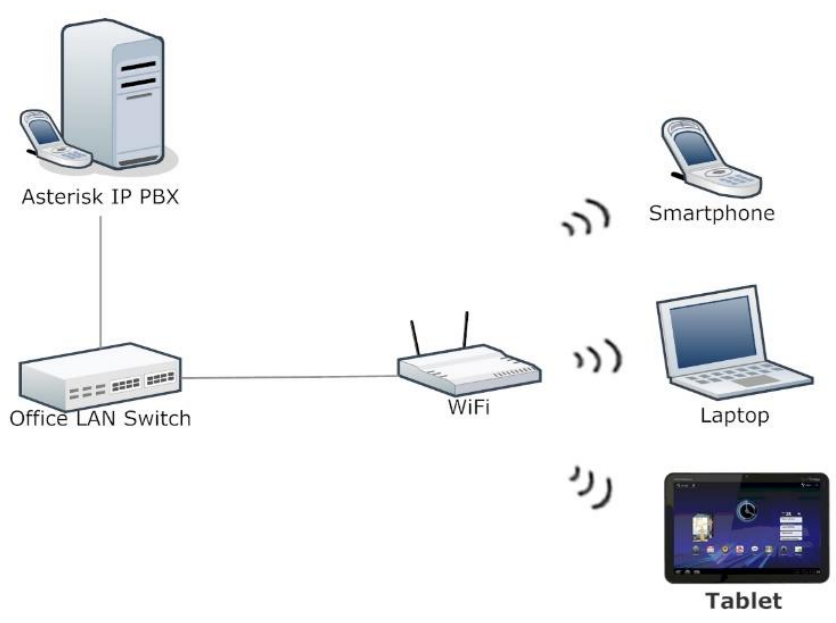

Gambar 1. Rancang Bangun VoIP

Gambar 1 menunjukkan bagaimana topologi VoIP Server bekerja. Beberapa perangkat seperti laptop dan smartphone yang masing-masing sudah ter-install softphone yang menjadi VoIP Client dan saling terhubung ke dalam jaringan lokal membentuk sebuah komunikasi VoIP yang dihubungkan oleh switch dengan sebuah server Trixbox. Skema client ini akan melakukan beberapa model panggilan seperti berikut:

1. PC (Windows) ke PC (Ubuntu)

2. $\quad \mathrm{PC}$ (Windows) ke Android/Tablet

3. $\mathrm{PC}$ (Ubuntu) ke PC (Windows)

4. $\quad \mathrm{PC}$ (Ubuntu) ke Android/Tablet

5. Android/Tablet ke PC (Windows)

6. Android/Tablet ke PC (Ubuntu)

VoIP Server menggunakan sistem operasi Linux Server. Penggunaan Linux disini menggunakan distributor (distro) Trixbox yang khusus digunakan untuk menangani VoIP. Jenis distro ini dipilih dikarenakan atas kesetabilan dan kehandalan dari Trixbox yang merupakan distro turunan dari CentOS. Proses desain sistem pada sisi server ada beberapa tahap. Tahap-tahap desain sistem pada sisi server bisa dilihat pada Gambar 2, dimulai dari instalasi Tribox CE hingga alokasi IP client.

Gambar 2 menunjukkan bahwa proses pertama adalah instalasi Trixbox versi 2.8.0.4 pada PC yang dikhususkan untuk VoIP Server. Kemudian dilanjutkan dengan mengkonfigurasikan jaringan sesuai dengan perancangan yang akan dibuat, diikuti dengan pengecekan koneksi VoIP Server melalui network interface yang digunakan serta sambungan ke Access Point sehingga VoIP Server dapat diakses oleh client yang ingin menggunakan telepon sambungan yang disediakan oleh VoIP Server. Selanjutnya
VoIP Server dapat mengalokasikan VoIP Client yang sudah terhubung dengan jaringan lokal dengan cara mendaftarkan nomor telepon extension client.

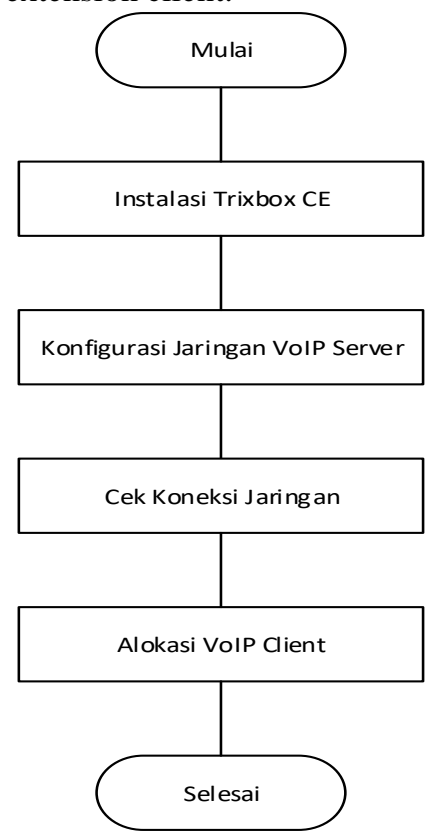

Gambar 2. Flowchart Desain Sistem Pada Sisi Server

Desain sistem pada sisi Client dengan menyiapkan laptop/smartphone agar mampu melakukan dan menerima panggilan melalui VoIP Server. Proses desain sistem pada sisi client ada beberapa tahap. Tahap-tahap desain sistem pada sisi client dapat dilihat pada gambar 3 .

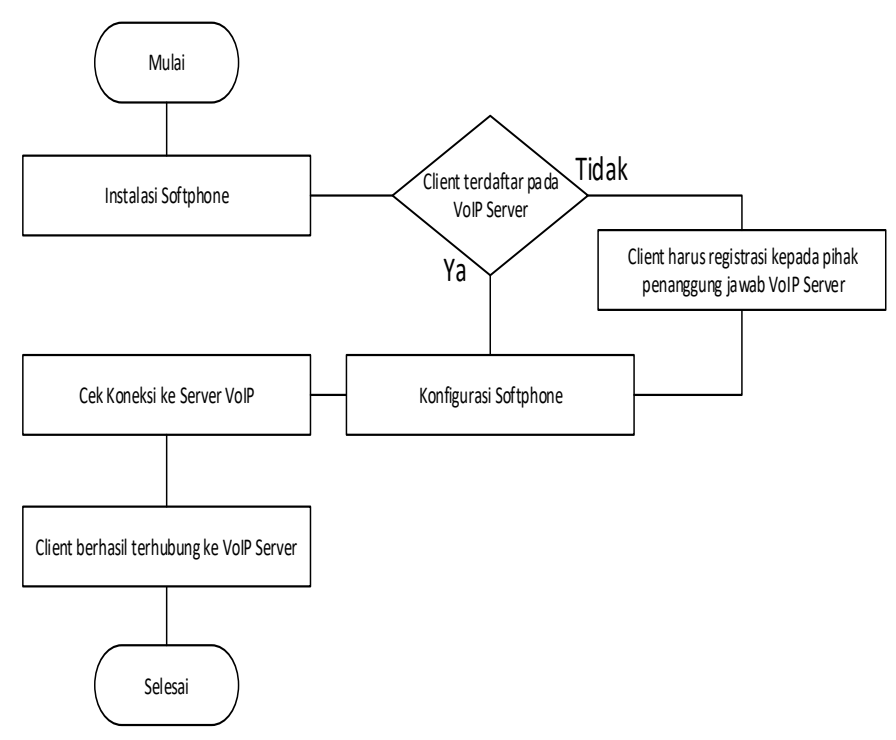

Gambar 3. Flowchart Desain Sistem Pada Sisi Client

Gambar 3 menunjukkan bahwa proses pertama dalam menentukan sebuah VoIP Client adalah dengan instalasi softphone, yaitu software yang digunakan untuk dapat berkomunikasi melalui VoIP Server kepada VoIP Client lain 
yang terhubung. Jika VoIP Client belum terdaftar pada VoIP Server maka client harus mendaftarkan diri terlebih dahulu untuk dapat mengakses sistem VoIP. Kemudian mengaktifkan softphone dengan cara mengkonfigurasikan softphone sesuai akun VoIP yang didaftarkan. Secara otomatis softphone akan melakukan cek koneksi terhadap request yang dikirim oleh VoIP Client kepada VoIP Server, setelah VoIP Server menerima data request dengan benar dan sesuai maka softphone berhasil dikonfigurasikan serta softphone sudah dapat melakukan atau menerima panggilan kepada VoIP Client lain yang terdaftar.

Dalam perancangan jaringan VoIP ini, penulis menggunakan topologi sederhana yang menggunakan beberapa perangkat yang terkoneksi dengan sebuah Access Point yang menghubungkan antara client dengan server VoIP. Topologi dapat dilihat pada gambar 4 .

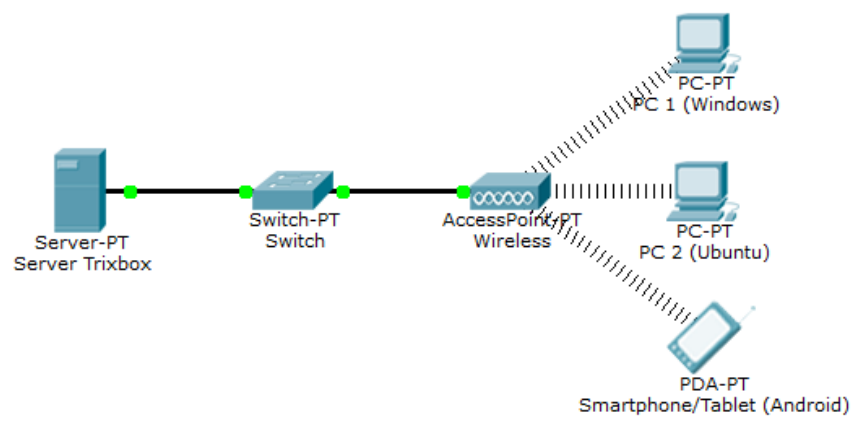

Gambar 4. Topologi Server VoIP

Pemetaan IP Address dilakukan supaya penggunaan alamat IP Address pada client dapat disortir dan dapat meminimalisir terjadinya IP conflict pada suatu jaringan. IP Address merupakan sebuah hal yang sangat penting, karena jika terjadinya IP conflict maka akan dapat mengganggu aktifitas host yang terlibat. Hal ini merupakan sebuah gangguan didalam koneksi jaringan, karena IP Address merupakan sebuah alamat yang digunakan oleh client yang terkoneksi ke jaringan kepada server pusat yang terhubung. Pada tahap ini, kelas IP Address yang akan digunakan adalah IP Address kelas C. Karena IP Address kelas C dapat menampung client sampai dengan 254 host.

TABEL I

PEMETAAN IP ADDRESS

\begin{tabular}{|l|l|}
\hline IP Address Host Min & 192.168 .100 .1 \\
\hline IP Address Host Max & 192.168 .100 .254 \\
\hline IP Netmask & 255.255 .255 .0 \\
\hline IP Broadcast & 192.168 .100 .255 \\
\hline IP Network & 192.168 .100 .0 \\
\hline Jumlah Host & 254 Host \\
\hline
\end{tabular}

\section{IMPLEMENTASI DAN HASIL}

Setelah seluruh proses instalasi dan konfigurasi selesai, maka dilanjutkan dengan pengujian komunikasi client VoIP, sehingga antar client dapat melakukan panggilan kepada client lain yang terhubung dalam jaringan VoIP Server.
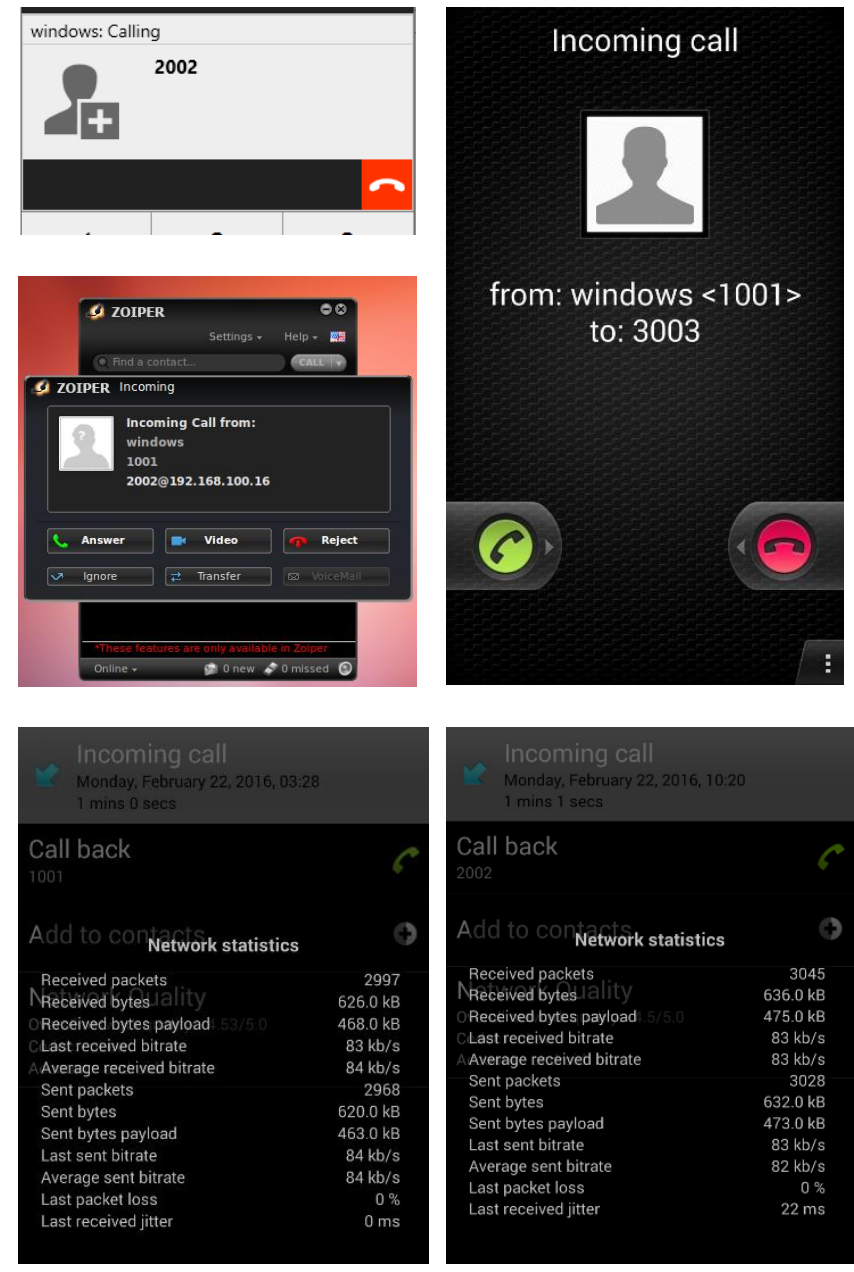

Gambar 5. Implementasi dan Hasil VoIP

Pada aplikasi ZoIPer IAX SIP di Android, memiliki sedikit kelebihan yang didapatkan yaitu dapat memperlihatkan secara langsung statistik mengenai percakapan yang dilakukan oleh client mulai dari packet, jitter, payload, dan bitrate dalam satu panggilan.

TABEL II

PENGUJIAN KOMUNIKASI CLIENT VOIP

\begin{tabular}{|l|l|l|l|}
\hline No & Nama Pengujian & Indikator Pengujian & Ket \\
\hline 1 & $\begin{array}{l}\text { Mengecek } \\
\text { konfigurasi antar } \\
\text { client VoIP. }\end{array}$ & $\begin{array}{l}\text { Terdapat status “account } \\
\text { registered" pada softphone }\end{array}$ & Berhasil \\
\hline 2 & $\begin{array}{l}\text { Client Windows } \\
\text { berkomunikasi } \\
\text { dengan } \text { client Ubuntu }\end{array}$ & $\begin{array}{l}\text { Client Windows } \\
\text { menghubungi nomor 2002 }\end{array}$ & Berhasil \\
\hline
\end{tabular}




\begin{tabular}{|c|c|c|c|}
\hline 3 & $\begin{array}{l}\text { Client Windows } \\
\text { berkomunikasi } \\
\text { dengan client } \\
\text { Android. }\end{array}$ & $\begin{array}{l}\text { Client Windows } \\
\text { menghubungi nomor } 3003\end{array}$ & Berhasil \\
\hline 4 & $\begin{array}{l}\text { Client Ubuntu } \\
\text { berkomunikasi } \\
\text { dengan client } \\
\text { Windows. }\end{array}$ & $\begin{array}{l}\text { Client Ubuntu } \\
\text { menghubungi nomor } 1001\end{array}$ & Berhasil \\
\hline 5 & $\begin{array}{l}\text { Client Ubuntu } \\
\text { berkomunikasi } \\
\text { dengan } \text { client } \\
\text { Android. }\end{array}$ & $\begin{array}{l}\text { Client Ubuntu } \\
\text { menghubungi nomor } 3003\end{array}$ & Berhasil \\
\hline 6 & $\begin{array}{l}\text { Client Android } \\
\text { berkomunikasi } \\
\text { dengan client } \\
\text { Windows. }\end{array}$ & $\begin{array}{l}\text { Client Android } \\
\text { menghubungi nomor } 1001\end{array}$ & Berhasil \\
\hline 7 & $\begin{array}{l}\text { Client Android } \\
\text { berkomunikasi } \\
\text { dengan client Ubuntu. }\end{array}$ & $\begin{array}{l}\text { Client Android } \\
\text { menghubungi nomor } 2002\end{array}$ & Berhasil \\
\hline
\end{tabular}

\section{KESIMPULAN}

\section{A. Kesimpulan}

1. VoIP Server Trixbox berperan menangani panggilan SIP dari seluruh client yang terdaftar kedalam server Trixbox.

2. Antara VoIP client dapat saling berkomunikasi dua arah ketika sudah terdaftar kedalam server Trixbox.

3. VoIP client dapat menggunakan layanan VoIP dari beberapa macam OS dan jenis perangkat, sehingga tidak akan berpengaruh terhadap pengguna yang menggunakan banyak jenis perangkat karena hanya tergantung dari extension client yang terdaftar yang digunakan.

4. Server Trixbox dapat di-remote melalui web base GUI sehingga user tidak perlu kemampuan khusus dalam pemrograman karena user interface yang sudah friendly.

\section{B. Saran}

1. Hendaknya VoIP ini dapat digabungkan dengan teknologi PSTN dengan tambahan VPN untuk keamanannya sehingga tidak hanya dapat digunakan pada jaringan lokal, namun juga dapat digunakan untuk melakukan panggilan ke jaringan PSTN.

2. Penggunaan VoIP merupakan solusi alternatif komunikasi masa depan, oleh karena itu untuk pengembangan selanjutnya dapat dilakukan analisis performansi VoIP dengan VoIP Monitoring.

3. Hendaknya pada teknologi VoIP ini lebih diperhatikan lagi dari segi keamanannya, sehingga tidak ada seorang pun yang dapat menyadap komunikasi antar client dengan maksud yang tidak diinginkan.

\section{DAFTAR PUSTAKA}

[1] M. Taufiq, "Membuat SIP Extensions Pada Linux TrixBox untuk Server VoIP", 2008

[2] O.W. Purbo, and A. Raharja, "VoIP Cookbook Building Your Own Telecommunication Infrastructure", 2010.

[3] T. Tharom, and O.W.Purbo,"Teknologi VoIP," Jakarta: PT. Elex Media Komputindo, 2010.

[4] W. Atmono, "Rancang Bangun Security pada Sistem VoIP OpenSource Trixbox," Tugas Akhir, Politeknik Negeri Semarang, 2008

[5] A. Nurkholis, A. Hendrawan. "Implementasi Server VoIP untuk Komunikasi di PT. Lintas Data Prima". Tugas Akhir. STIMIK Amikom Yogyakarta. 2011.

[6] Mustaqim, F., Solikin, S. M., \& Anang Sularsa, S. (2012). Implementasi VoIP Over VPN Menggunakan IPv4 (Studi Kasus Politeknik Telkom). Politeknik Telkom.

[7] Thamrin, H., Susilo, H. T., \& Kusban, M. (2013). Kualitas Layanan Sistem VOIP di Kabupaten Sragen Dibanding Sistem Alternatif dengan Server Trixbox.

[8] D. Collins, "Carrier Grade Voice Over IP," United States, Mc Graw Hill, 2001.

[9] M. Colliers, and D. Endler, "Hacking Exposed Unified Communication \& VoIP Security Secrets \& Solutions," United States, Mc Graw Hill, 2013.

[10] Sany, R. S. (2009). Teknik Keamanan Voice over WLANs 802.11. Universitas Sumatra Utara. 